\title{
VOLTAMMETRIC ANALYSIS OF HYDROQUINONE IN SKIN WHITENING COSMETIC USING FERROCENE MODIFIED CARBON PASTE ELECTRODE
}

\author{
M. Harsini ${ }^{1}{ }^{*}$, U. Untari ${ }^{1,2}$, E. Fitriany ${ }^{1,4}$, A. N. Farida ${ }^{1}$, M. Z. Fahmi ${ }^{1}$, \\ S.C.W. Sakti ${ }^{1}$, and G. Pari ${ }^{3}$ \\ ${ }^{1}$ Department of Chemistry, Faculty of Science and Technology, Universitas Airlangga, \\ Kampus C Mulyorejo, Surabaya 60115, Indonesia \\ ${ }^{2}$ Health Analyst Vocation Study Program, Health School Papua, Sorong City, \\ West Papua, Indonesia \\ ${ }^{3}$ Forest Product Research and Development Center, Ministry of Environment and Forestry, \\ Jakarta, Indonesia \\ ${ }^{4}$ Faculty of Formal and Application Science, Universitas Muhammadiyah Madiun, Indonesia \\ *E-mail: muji-h@fst.unair.ac.id
}

\begin{abstract}
Hydroquinone is the most effective whitening agent in skin whitening cosmetics. It has the ability to whiten the skin in a relatively shorter time compared to other whitening agents. However, based on the regulations of the Indonesian Food and Drug Administration (BPOM) and the United States Food and Drug Administration (FDA), the use of hydroquinone in whitening cosmetics is prohibited and is given zero tolerance. Therefore, it is the aim of this study to develop an alternative method to analyze the presence of hydroquinone in cosmetics that is easier, inexpensive, selective, and accurate. The result showed that the best composition of the electrode membrane which gave the best outcome was carbon: paraffin: ferrocene with each ratio of $6: 3: 1$. The validity of the hydroquinone analysis method that uses carbon/ferrocene paste as the electrode shows good results with the working range of $0.20-10 \mu \mathrm{M}$, the sensitivity of $10.436 \mu \mathrm{A} / \mu \mathrm{M}$, and detection limit of $0.06 \mu \mathrm{M}$. It is also selective in the analysis of a mixture of hydroquinone and arbutin. These electrodes have excellent accuracy in recovering hydroquinone analysis in cosmetic samples with an average recovery value of $99 \%$. This electrode can also be used for arbutin analysis in cosmetics with an accuracy of $99 \%$. This method is suitable to be used in skin whitening analysis, both hydroquinone and arbutin.
\end{abstract}

Keywords: Hydroquinone, Arbutin, Voltammetry, Ferrocene, Cosmetics, Whitening Agent

(C) RASĀYAN. All rights reserved

\section{INTRODUCTION}

Hydroquinone is one of the most effective whitening agents compared to other whitening agents because it has the ability to whiten the skin in a relatively short time with only low concentration. ${ }^{1}$ However, based on the regulations of the Indonesian Food and Drug Administration and the Food And Drug Administration (FDA), the use of hydroquinone in whitening cosmetics is prohibited and is given zero tolerance due to its negative impact on health. ${ }^{2}$ There are many side effects of using hydroquinone in whitening cosmetics such as skin irritation, skin redness, burning sensation, and black patches on the skin. Meanwhile, the long-term side effects of hydroquinone can lead to skin cancer, kidney and liver function disorders. ${ }^{1}$ However, in case of medical purposes such as treatment of hyperpigmentation, hydroquinone is still permitted under the strict supervision of a doctor because hydroquinone is on the list of hard drugs. ${ }^{3}$

The Indonesian Food and Drug Supervisory Agency notes that there are still many labeled whitening cosmetics containing hydroquinone. Those whitening cosmetics are also circulating illegally on the market, not to mention that the concentration level is relatively high which is more than $2 \%$. Odumosu \& Ekwe (2010) analyzed the presence of hydroquinone in 10 whitening cosmetics on the market and they

Rasayan J. Chem., 12(4), 2296-2305(2019)

http://dx.doi.org/10.31788/RJC.2019.1245479

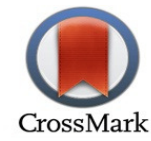


were all tested positive in containing hydroquinone ranging from $2 \%$ to $5 \%$ of concentration level. ${ }^{4} \mathrm{~A}$ similar test was done by Siddique et al. (2012) who found that 11 out of the 22 whitening cosmetics analyzed were tested positive in containing hydroquinone with various concentration levels ranging from $0.002 \%$ to $0.092 \%{ }^{5}$ Based on the result of several tests, it was proven that the use of hydroquinone in skin whitening cosmetics is still widely used and circulated in the community. Therefore, it is needed to develop a faster method that is also inexpensive and accurate to detect the use of hydroquinone in cosmetics. The method is expected to be the first step in preventing and controlling the negative effects caused by the use of these compounds.

Various methods have been developed for hydroquinone analysis, including High-Performance Liquid Chromatography (HPLC), ${ }^{6}$ GC-MS, ${ }^{7}$ Chemiluminescence Flow Injection, ${ }^{8}$ Capillary electrophoresis ${ }^{9}$ and Spectrophotometry. ${ }^{4}$ Some of the methods that have been developed have good sensitivity, but have complicated sample preparation stages and relatively expensive analytical costs. This is what drives the need for the development of hydroquinone analysis methods that are not only easier, cheaper, faster, and more efficient, but are also sensitive, selective and accurate. Hydroquinone is an electroactive compound that can undergo oxidation and reduction reactions so that it can be detected by electrometry. The development of hydroquinone analysis using the voltammetry method has been carried out by developing various types of working electrodes..$^{10-15}$

In this study, the working electrode used was carbon paste electrode (CPE) which was modified by ferrocene $(\mathrm{Fc})$. The application of carbon as a working electrode is based on the inert nature of carbon. A good conductive material that has a wide potential range besides carbon is also cheap and easy to obtain. ${ }^{16}$ Ferrocene functions as a mediator to increase the electrocatalytic activity of redox reactions. ${ }^{17}$ Ferrocene that is used as a mediator of the voltammetry method has been carried out in the analysis of dopamine $^{17}$ and levodopa ${ }^{18}$. Based on the result of several studies, the addition of ferrocene increased the sensitivity of analyte measurements. The selectivity of the Fc / CPE electrode was studied by the detection of hydroquinone in its mixture with the skin whitening compound named arbutin (hydroquinone- $\beta$-D-glukopyranoside) since these compounds are widely used as a substitute for hydroquinone. Based on the result of the study, arbutin compounds can be hydrolyzed to hydroquinone by the skin's bacterial activity. ${ }^{19}$

\section{Chemicals and Reagents}

\section{EXPERIMENTAL}

Activated carbon was obtained from the Forest Products Research and Development Center, Bogor, Indonesia. This carbon is made from teak wood (Tectona grandis) which is activated at a temperature of $850{ }^{\circ} \mathrm{C}$ for 120 minutes. Ferrocene and hydroquinone were purchased from Sigma. All other used materials were in an analytical reagent grade.

\section{Apparatus}

Voltammetric experiments were performed using a potentiostat edaq e-corder 201 (model ed201) which is equipped with 3 pieces of electrodes, namely the reference electrode $(\mathrm{Ag} / \mathrm{AgCl})$, auxiliary electrode $(\mathrm{Pt})$, and ferrocene modified carbon paste $(\mathrm{Fc} / \mathrm{CPE})$ as the working electrode.

\section{Electrode Preparation}

The electrodes were prepared by mixing carbon, paraffin pastilles, and ferrocene with variations in the composition of ferrocene $(\mathrm{w} / \mathrm{w})$. Electrodes with a composition of $10 \%$ ferrocene consist of carbon, paraffin, and ferrocene with a ratio of 6: $3: 1$. Other compositions are regulated by changing the amount of ferrocene and carbon, while paraffin is fixed. The mixture in the watch glass was heated at $40{ }^{\circ} \mathrm{C}$ using a hotplate until the paraffin melts, then the mixture was stirred to form a paste. The warm paste than was inserted into the micropipette tip (electrode body) which has been installed with copper wire and later it was pressed until there was no empty space in it. Afterward, the electrode surface was rubbed on HVS paper until it shines which indicates that the electrode surface is flat and smooth.

\section{Measurement Voltammetry}

Ferrocene/CPE was used as working electrode, $\mathrm{Ag} / \mathrm{AgCl}$ was used as reference electrode, while platinum was used for the auxiliary electrode. The three electrodes were dipped in $1 \mathrm{mM}$ hydroquinone 
solution using the cyclic voltammetry $(\mathrm{CV})$ technique in the potential range of $-0.2 \mathrm{~V}$ to $+1.0 \mathrm{~V}$ in order to study the effect of $\mathrm{pH}$ and scan rate. Linear sweep voltammetry (LSV) in the same potential range was used for quantitative analysis and validation. A phosphate buffer solution (PBS) is used to adjust the $\mathrm{pH}$ of the solution.

\section{Sample Preparation}

The sample used was a cosmetic cream free of whitening agent that later spiked with hydroquinone until the concentration reached $2 \%$. It was then diluted and immediately analyzed using the LSV technique. In the same way, a cream that is routinely spiked with hydroquinone until the concentration reached $4 \%$ was also being diluted quantitatively and analyzed by LSV to determine accuracy.

\section{Characterization}

\section{RESULTS AND DISCUSSION}

The Scanning electron microscopy (SEM) of the teak wood carbon (Tectona grandis) which was activated by heating at $850{ }^{\circ} \mathrm{C}$ for 120 minutes shows that the activated carbon has various pore sizes and shapes (Fig.-1) and BET surface area was $861.900 \mathrm{~m}^{2}$. Cyclic voltammogram in Fig. -2 and Table 1 data show that the value of $\Delta E_{p}$ in hydroquinone analysis with the Ferrocene/CPE electrode is in a smaller number compared to the value of $\Delta E_{p}$ on $\mathrm{CPE}$ electrode. This indicates that the Fc/CPE electrode provides better reversibility compared to the CPE electrode.

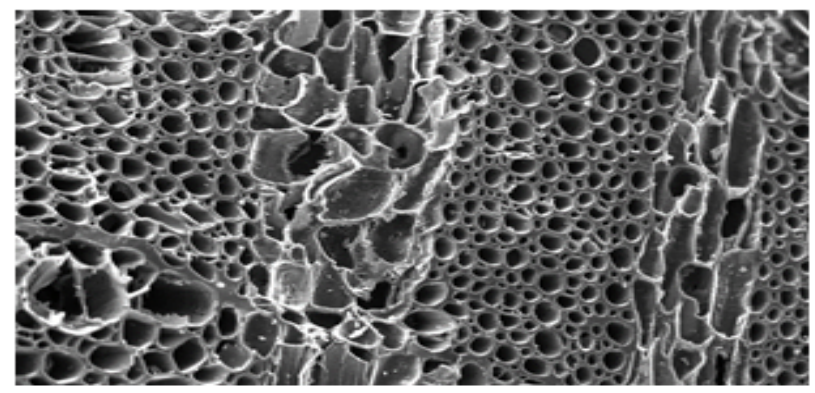

Fig.-1: SEM Image of the Activated Carbon

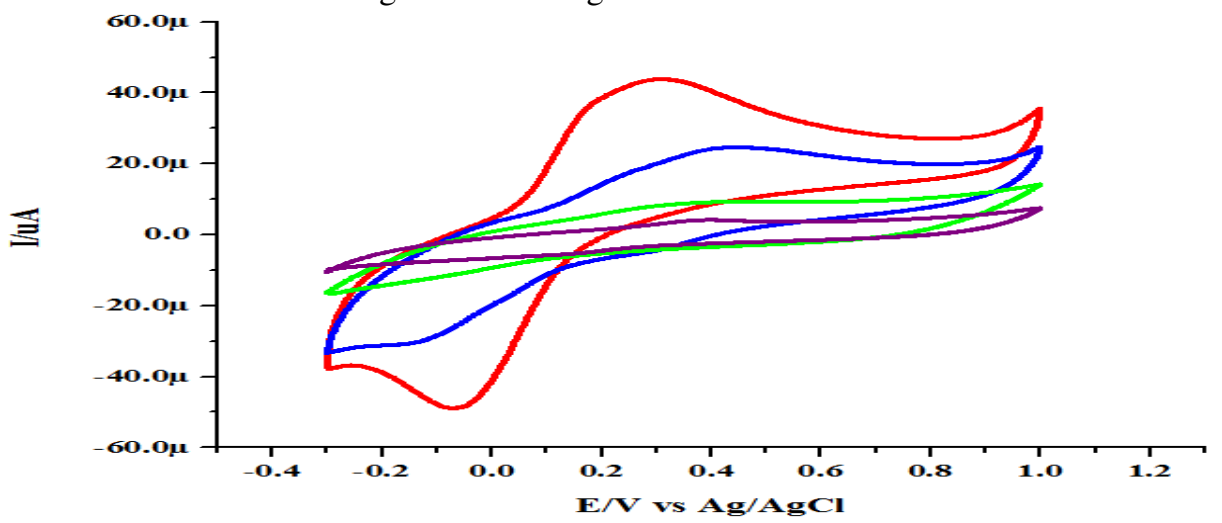

(a) Hydroquinone with $\mathrm{CPE}$
(b) Hydroquinone with Fc/CPE
(c) $\mathrm{pH} 7$ phosphate buffer with Fc/CPE
(d) $\mathrm{pH} 7$ phosphate buffer with $\mathrm{CPE}$

Fig.-2: Cyclic Voltammogram of $1 \mathrm{mM}$ Hydroquinone in $\mathrm{pH} 7 \mathrm{PBS}$ with a Scan Rate of $100 \mathrm{mV} / \mathrm{s}$ by using 10 $\% \mathrm{Fc} / \mathrm{CPE}$ and $\mathrm{CPE}$ Electrodes

Ferrocene functions as a mediator for electron transfer, so that the electrons received and released in the reduction and oxidation reactions on the surface of the working electrode are faster. ${ }^{17}$ The buffer solution functions as a supporting electrolyte that does not electroactive so it does not provide peak current. 
RASĀYAN J. Chem.

Vol. 12 | No. 4 |2296 - 2305| October - December | 2019

Table-1: Data on $E p_{a}, E p_{c}, I p_{a}, I p_{c}$ and $\Delta E_{p}$ of $1 \mathrm{mM}$ Hydroquinone Analysis

\begin{tabular}{c|c|c|c|c|c}
\hline Electrode & $E_{p a}(\mathrm{mV})$ & $E_{p c}(\mathrm{mV})$ & $\Delta E p(\mathrm{mV})$ & $I_{p a}(\mu \mathrm{A})$ & $I_{p c}(\mu \mathrm{A})$ \\
\hline $\mathrm{Fc} / \mathrm{CPE}$ & 0.297 & -0.060 & 0.357 & 31.880 & -27.960 \\
\hline $\mathrm{CPE}$ & 0.410 & -0.137 & 0.547 & 12.567 & -7.630 \\
\hline
\end{tabular}

The magnitude of the separation value of anodic and cathodic peak potential $\left(\Delta E_{p}\right)$ can be used to determine the number of the transferred electrons during the voltammetry hydroquinone analysis process. The value of $\Delta E_{p}$ can also be used as a determinant of the reversibility criteria of the reaction. ${ }^{20}$ In addition to showing a smaller separation of peak potential $\left(\Delta E_{p}\right)$, hydroquinone analysis with $\mathrm{Fc} / \mathrm{CPE}$ working electrodes produces anodic and cathodic current peaks that are 2.5 times higher than using CPE. It indicates that with the addition of Ferrocene, the transfer speed of the electrons to the electrode surface becomes faster which allows greater production of electrode sensitivity and results in the higher current. The proposed mechanism for catalytic reaction on the Fc/CPE in hydroquinone analysis is as follows:

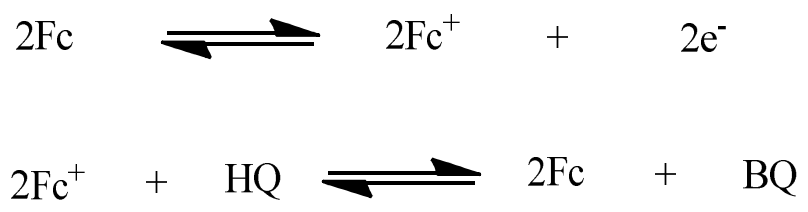

When the Fc /CPE is electrified from a negative potential to a positive potential, the Ferrocene contained in the working electrode is oxidized to form an $\mathrm{Fc}^{+}$ion. This ion then oxidizes hydroquinone (HQ) to form benzoquinone (BQ) by releasing 2 electrons while the $\mathrm{Fc}^{+}$ion is reduced by taking 2 electrons to form Fc. The occurrence of electron transfer during the oxidation process and the reduction of the analyte on the surface of the working electrode voltammetry produces a current response that is proportional to the amount of concentration of the analyte in the solution. The description of the hydroquinone reaction on the Fc/CPE surface can be seen in Fig.-3.
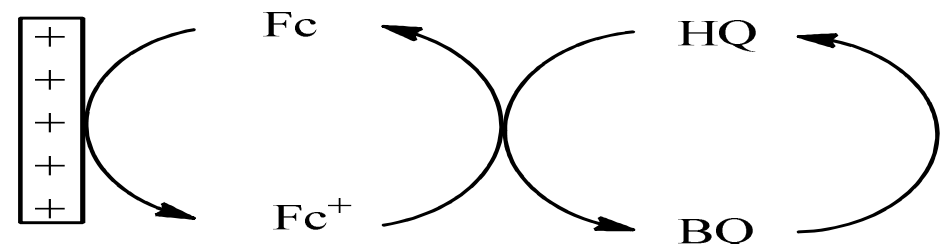

Fig.-3: Model of the Hydroquinone Reaction on Fc/CPE

In addition, to demonstrate the effectiveness of hydroquinone analysis, the Fc/CPE electrode also showed good stability in the solution. The result of $1 \mathrm{mM}$ hydroquinone analysis with repetitive measurements by 20 cycles can be seen in Fig.- 4.The voltammogram shows that by repeating the measurement of $1 \mathrm{mM}$ hydroquinone in 20 cycles, there was no significant change in both anodic $\left(E_{p a}\right)$ and anodic $\left(I_{p a}\right)$ peak potential. The stability of electrocatalytic activity from the electrodes modified with Ferrocene indicates that the Ferrocene contained in the working electrode is insoluble and stable.

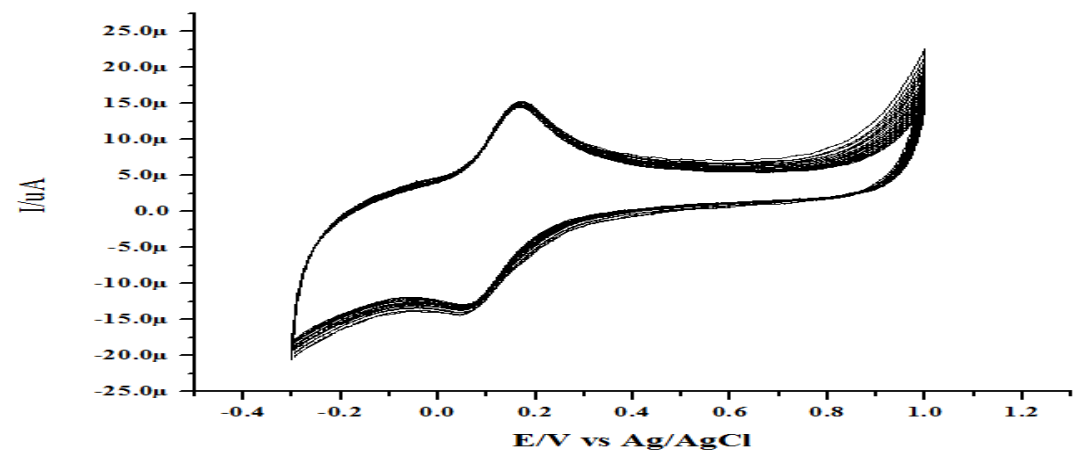

Fig.-4: Cyclic Voltammogam of $1 \mathrm{mM}$ Hydroquinone Voltammogram using Fc/CPE Electrode with 20 Cycles of Repeated Measurements 


\section{Optimization of Working Electrode Composition}

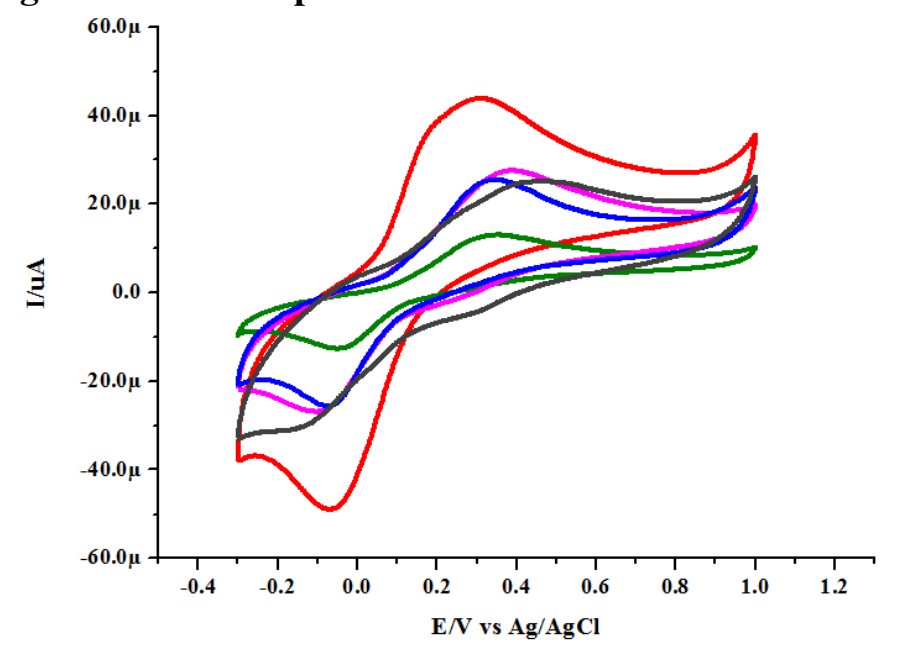

$$
\begin{aligned}
& 0 \% \text { ferrocene } \\
& 5 \% \text { ferrocene } \\
& 10 \% \text { ferrocene } \\
& 15 \% \text { ferrocene } \\
& 20 \% \text { ferrocene }
\end{aligned}
$$

Fig.-5: Cyclic Voltammogram Influences the Composition of the Working Electrode on the Measurement of $1 \mathrm{mM}$ Hydroquinone Solution in pH 7 PBS with a Scan Rate of $100 \mathrm{mV} / \mathrm{s}$

The voltammogram in Fig.- 5 shows that the amount of Ferrocene in the working electrode composition influences the voltammetric response analysis of $1 \mathrm{mM}$ hydroquinone in $\mathrm{pH} 7$ of phosphate buffer. The addition of ferrocene in the working electrode increases the anodic current peak value and reaches the maximum value of $10 \%$ ferrocene composition so that this composition was selected as the electrode in the subsequent analysis. These results indicate that a higher amount of Ferrocene in the working electrode produces higher peak currents of the anodic and cathodic since they act as electron transfer mediators.In addition to the peak current height, the reversibility of the reaction at the electrode surface must be considered. A voltammogram with a composition of $0 \%$ ferrocene gives a peak current higher than a peak current of 5\% ferrocene, but has lower reversibility than an electrode with a composition of 5\% ferrocene. Reversibility of the reaction can be seen from the distance between the anodic $\left(E_{p a}\right)$ and cathodic peak potential $\left(E_{p c}\right)$. Adjacent distances indicate increasingly close to the reversible reaction. However, it is also notable that if the composition of the working electrode is added with Ferrocene of more than $10 \%$, then the peak current decreases. It happened since there was an excessive amount of Ferrocene that therefore causes the carbon contained in the electrode composition to become less which leads to the decreasing electrical conductivity of the working electrode. The decreasing conductivity of the electrode affects the transfer of electrons on the surface electrode.

\section{Effect of Scan Rate}

The effects of scan rates were studied in the range of 10 to $250 \mathrm{mV} / \mathrm{s}$. The cyclic voltamogram of the scan rate effect on $1 \mathrm{mM}$ hydroquinone analysis is shown in Fig.-6.

Based on the voltammogram, a higher scan rate means higher production of $I_{p a}$ and $I_{p c}$ and both have a linear correlation. The linear relationship between scan rate and $I_{p a}$ and $I_{p c}$ is indicated by the value of the correlation coefficient $\left(R^{2}\right)$ which is close to 1 (Fig.-7). This correlation is in accordance with the theory that claims a faster scanning process during analyte analysis results in faster transfer of electrons to the electrode surface. As a consequence, the resulting current is also higher. The linear curve between $\log \mathrm{v}$ and $\log I_{p a}$ with a slope of 0.4477 , this value approaches 0.5 (Fig.-8) shows the control-diffusion reaction 
RASĀYAN J. Chem.

Vol. 12 | No. 4 |2296 - 2305| October - December | 2019

on the surface of the electrode. According to the theory, the slope value that is equal to 1 indicates adsorption process whereas if the slope value is between 0.5 and 1 hence it indicates the mixture of diffusion and adsorption processes. ${ }^{21}$

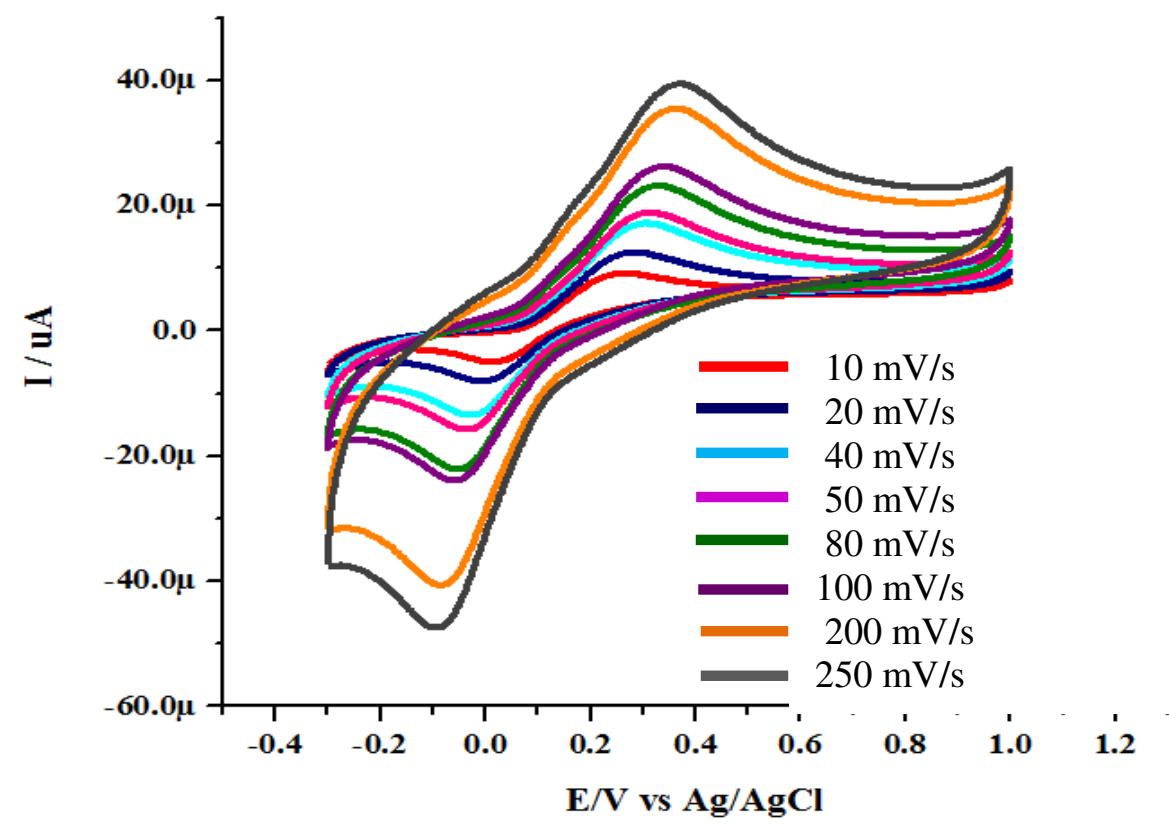

Fig.-6: Cyclic Voltammogram of the Scan Rate Effect on $1 \mathrm{mM}$ Hydroquinone Measurement in pH 7 with $10 \%$ Fc/CPE Electrode

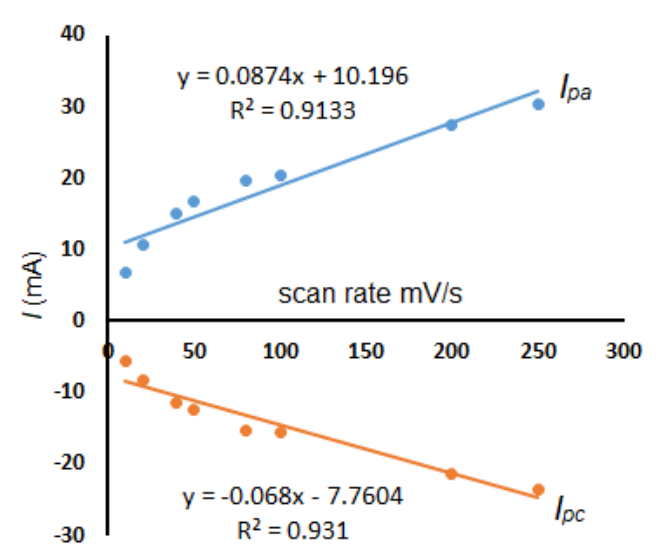

Fig.-7: The Relationship Between Curve $I p_{a}$ and $I p_{c}$ with the Scan Rate

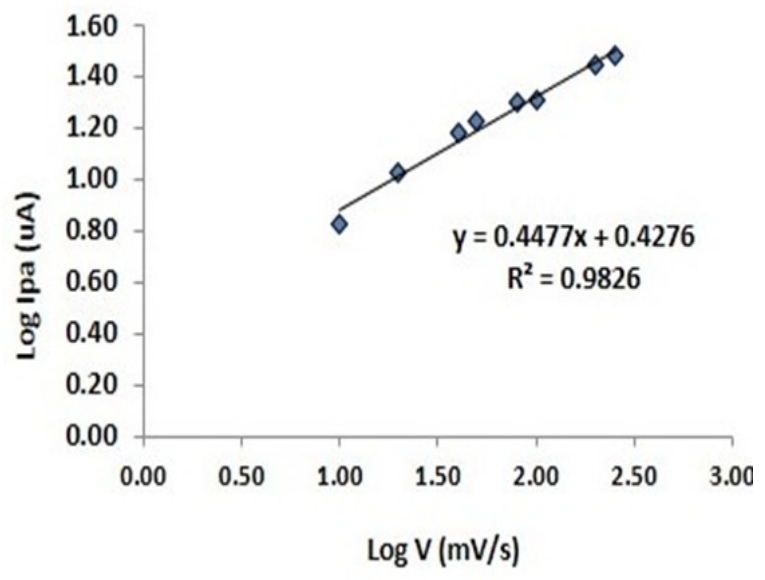

Fig.-8: The Relationship Between Curve $\log v$ with $\log I_{p a}$

\section{The Effect of pH on the Electrochemical Properties of Hydroquinone}

Figure-9 shows how the $\mathrm{pH}$ of the solution affects the anodic peak current $\left(I p_{a}\right)$ and the cathodic peak current $\left(I p_{c}\right)$ of $1 \mathrm{mM}$ hydroquinone. $I p_{a}$ and $I p_{c}$ values increase from $\mathrm{pH} 3$ and reach a maximum point at $\mathrm{pH}$ 7. It can also be seen that at a $\mathrm{pH}$ more than 7, the value of $I p_{a}$ and $I p_{c}$ decreases. This is because the increasing $\mathrm{pH}$ causes the amount of hydroxide ion in the solution to also increase, thereby reducing the hydroquinone adsorption capacity on the surface electrode. ${ }^{22}$ In addition, the decrease in $I p_{a}$ and $I p_{c}$ is also due to the alkaline $\mathrm{pH}$ conditions of hydroquinone that go trough an autoxidation reaction with oxygen molecules that in the end creates brownish 2-hydroxy-p-benzoquinone compounds. ${ }^{23}$ The hydroquinone oxidation reaction can be seen in Fig.-10.

Besides being seen from the highest value of $I_{p a}$ and $I_{p c}$, it is also noTable- that on the surface of the working electrode with its $\mathrm{pH}$ reaches 7 , a reaction occurs. This reaction shows the most reversible 


\section{RASĀYAN J. Chem.}

Vol. 12 | No. 4 |2296 - 2305| October - December | 2019

results. This can be seen from the value of $I_{p a l} I_{p c}$ which is the closest to 1 . However, the overall reaction on the surface of Ferrocene/CPE electrode in hydroquinone analysis with a range of $\mathrm{pH} 3$ to 8 shows a quasi-reversible reaction, because the value of $\Delta E$ is in the range $61 / \mathrm{n} \mathrm{mV}<\Delta E_{p}<212$. $^{24}$
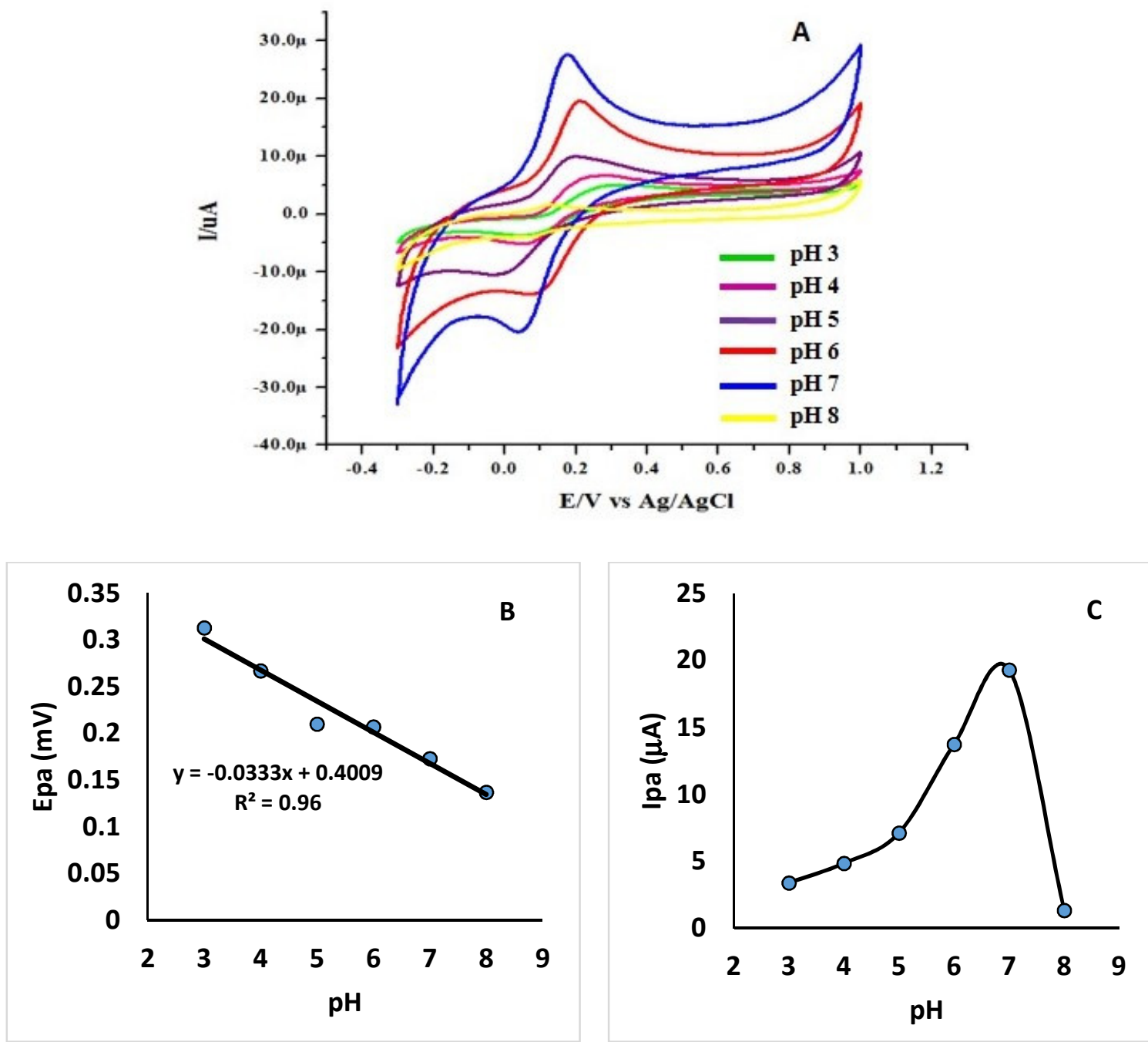

Fig.-9: (A) Cyclic Voltammogram Effect of pH Buffer on the Electrochemical Properties of $1 \mathrm{mM}$ Hydroquinone at a scan rate of $10 \mathrm{mV} / \mathrm{s}$, (B) the Effect of $\mathrm{pH}$ on Peak Potential Hydroquinone, and (C)

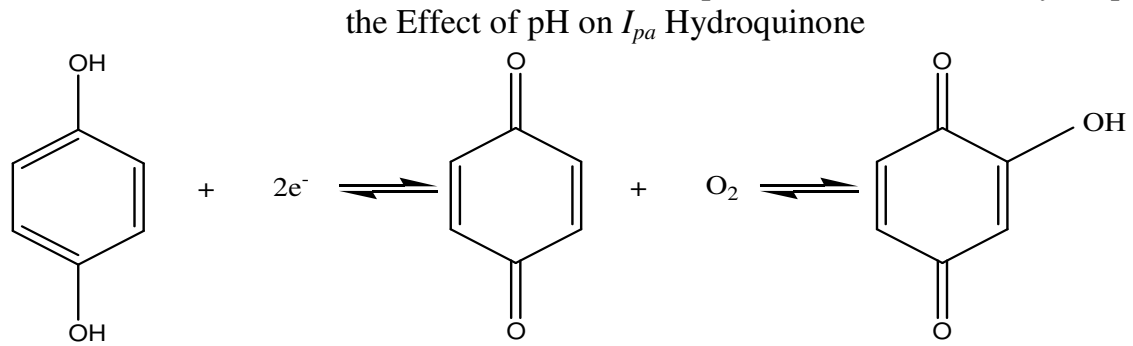

Fig.-10: Reaction of Hydroquinone Oxidation at Alkaline $\mathrm{pH}$

\section{Hydroquinone Linear Sweep Voltammetry (LSV)}

Figure-11 shows the LSV HQ voltammogram at various concentrations while the calibration curves are in the concentrations of $0.20-10.00 \mu \mathrm{M}$. The sensitivity value is shown from the slope of the linear 
RASĀYAN J. Chem.

Vol. 12 | No. 4 |2296 - 2305| October - December | 2019

regression equation. The figure indicates that each change in the concentration of $1 \mu \mathrm{M}$ hydroquinone results in a change of current in as much as $10.436 \mu \mathrm{A}$. Detection limit value in hydroquinone analysis which used Ferrosen/CPE electrode is $0.06 \mu \mathrm{M}$.Table-2 shows the LOD hydroquinone of this study compared to electrodes from several literature.
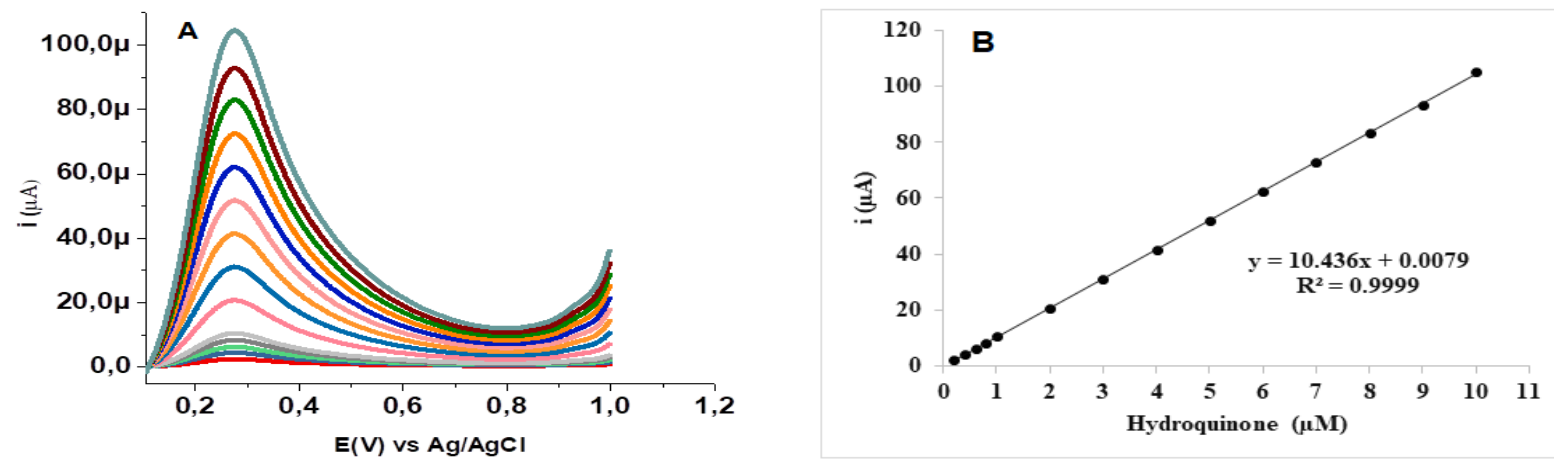

Fig.-11: (A) LSV Hydroquinone Voltammogram at a Concentration of $0.2-10 \mu \mathrm{M}$ with a Scan Rate of $100 \mathrm{mV} / \mathrm{s}$ and (B) a Curve of the Relationship between Concentration and Current.

Table-2: Comparison of Hydroquinone Measurements with Various Electrodes

\begin{tabular}{c|c|c|c|c}
\hline Electrode & Technique & Range & Sensitivity & LOD \\
\hline MET/AuNPs/GCE $^{10}$ & DPV & $8-400 \mu \mathrm{M}$ & $0.47 \mu \mathrm{A} / \mu \mathrm{M}$ & $0.12 \mu \mathrm{M}$ \\
\hline PEDOT/CNT/CPE $^{11}$ & DPV & $1.1-125 \mu \mathrm{M}$ & $0.25 \mu \mathrm{A} / \mu \mathrm{M}$ & $0.30 \mu \mathrm{M}$ \\
\hline $\mathrm{Au}-\mathrm{GR} / \mathrm{CILE}^{12}$ & $\mathrm{DPV}$ & $0.06-800 \mu \mathrm{M}$ & $0.10 \mu \mathrm{A} / \mu \mathrm{M}$ & $0.018 \mu \mathrm{M}$ \\
\hline $\mathrm{IL}^{\mathrm{CCPE}}{ }^{14}$ & $\mathrm{CV}$ & $0.01-10 \mathrm{mM}$ & $0.09546 \mathrm{~mA} / \mathrm{mM}$ & $8.1 \times 10^{-7} \mathrm{M}$ \\
\hline (ZLH-F)/MWCNTg $^{15}$ & $\mathrm{SWV}$ & $10-1000 \mu \mathrm{M}$ & $12.787 \mu \mathrm{A} / \mathrm{M}$ & $5.7 \mu \mathrm{M}$ \\
\hline Ferrocene/CPE (this work) & $\mathrm{LSV}$ & $0.2-10 \mu \mathrm{M}$ & $10.436 \mu \mathrm{A} / \mu \mathrm{M}$ & $0.06 \mu \mathrm{M}$ \\
\hline
\end{tabular}

\section{Selectivity}

For arbutin analysis, the electrode selectivity test was carried out by using Fc/CPE in $\mathrm{pH} 3$ solution. In this study, the concentration of arbutin varied from 0.2 to $10 \mu \mathrm{M}$. The resulting voltammogram is shown in Fig.-12.Based on the voltammogram, arbutin gives two peak potentials namely the potential of $0.213 \mathrm{~V}$ and $0.660 \mathrm{~V}$. Those two are the potential peaks of hydroquinone and arbutin which are completely separated. It was possible to happen since, in the water, arbutin undergo hydrolysis reactions to hydroquinone (Fig.-13). Thus, it can be concluded that Fc/CPE electrodes have good selectivity since it is able to distinguish hydroquinone and arbutin compounds. These electrodes can be used for hydroquinone or arbutin analysis, but cannot be used for the simultaneous analysis of both in mixtures.
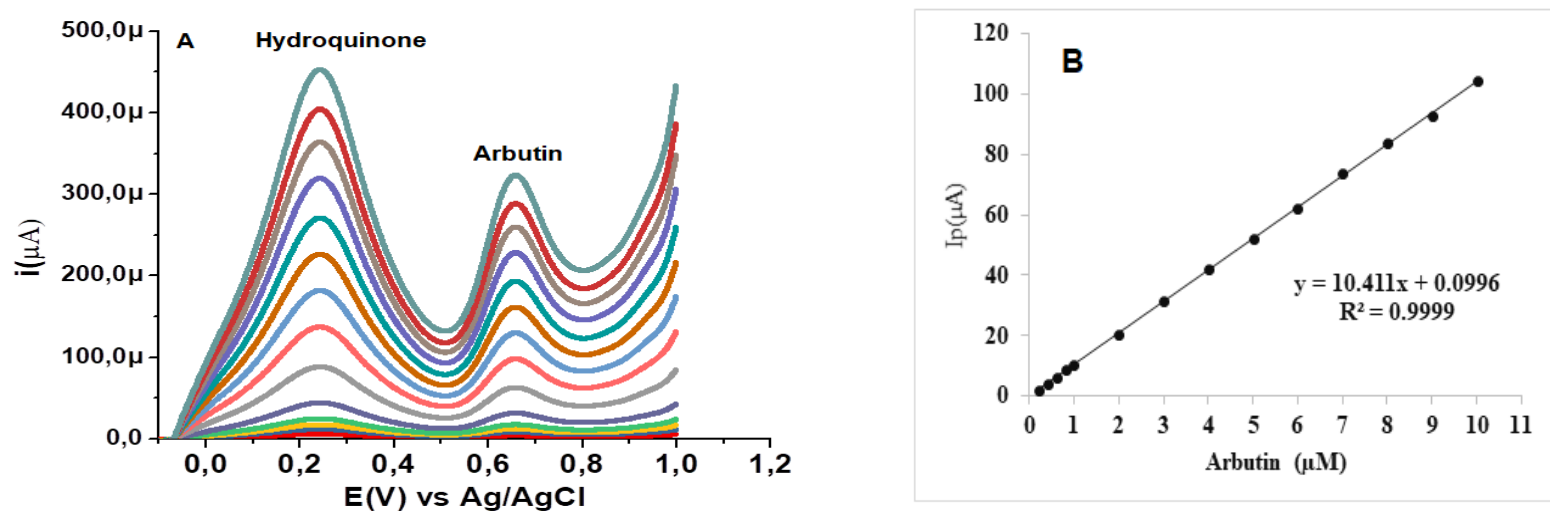

Fig.-12: LSV Voltammogram of Arbutin Variation in the Concentration that uses Fc / CPE Electrodes with a Scan Rate of $100 \mathrm{mV} / \mathrm{s}$ and Buffer Solution of pH 5. Voltammogram Gives Two Potential Peaks at 0.213

(Hydroquinone) and 0.660 (Arbutin) (A). The Curve of the Relationship between the Concentration of Arbutin and Peak Current (B) 
RASĀYAN J. Chem.

Vol. 12 | No. 4 |2296 - 2305| October - December | 2019

\section{Analysis of Hydroquinone and Arbutin that Are Added in Cosmetics}
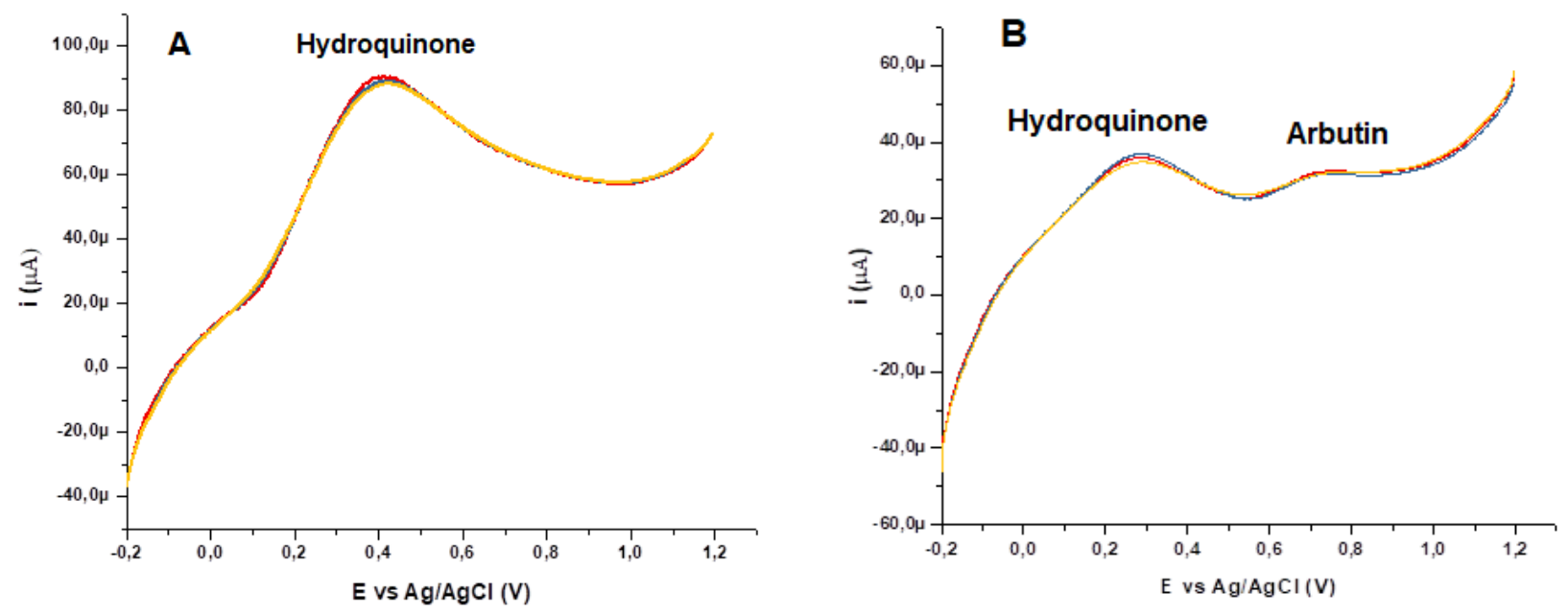

Fig.-13: LSV Voltammogram Analysis of Cosmetic Samples that are Spiked with Hydroquinone (A), and Arbutin (B) using $\mathrm{Fc} / \mathrm{CPE}$

The cosmetic samples used in the study were came from particular brand body lotion creams that did not contain skin whitening agents, both HQ and/or arbutin, and then spiked with hydroquinone so that the concentration percentage reached $2 \%$, while the other samples were added with arbutin so that the concentration percentage reached 4\%. Afterward, the samples were diluted quantitatively. The measurements were made three times by using the LSV technique with the help of Ferrocene/CPE electrodes. The resulting voltammogram is shown in Fig.-12. Based on the 12B voltammogram, it can be seen that the arbutin compound gives two oxidation peaks. The first peak is the oxidation peak of hydroquinone which reached $0.213 \mathrm{~V}$, while the second peak is the oxidation peak of arbutin which reached $0.660 \mathrm{~V}$. Table- 3 and 4 are the results of the analysis of hydroquinone and arbutin recovery in the cosmetic cream.

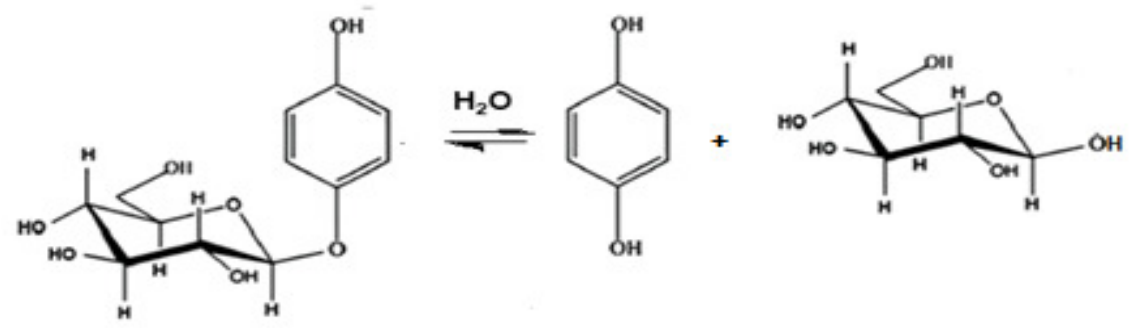

Fig.-14: Arbutin Hydrolysis to Hydroquinone Reaction

Table-3: Hydroquinone Analysis in Cosmetic Creams that were Hydroquinone-Spiked with Fc/CPE by Utilizing LSV Technique

\begin{tabular}{c|c|c|c}
\hline No & Spiking HQ $(\mathrm{g} / 10 \mathrm{~g})$ & Found $(\mathrm{g} / 10 \mathrm{~g})$ & \% Recovery \\
\hline 1 & 0.2003 & 0.1991 & 99.40 \\
\hline 2 & 0.2002 & 0.1949 & 97.35 \\
\hline 3 & 0.2003 & 0.1987 & 99.23 \\
\hline
\end{tabular}

Table-4: Arbutin Analysis in Cosmetic Creams that were Arbutin-Spiked with Fc/CPE by Utilizing LSV Technique

\begin{tabular}{c|c|c|c}
\hline No & Spiking Arbutin $(\mathrm{g} / 10 \mathrm{~g})$ & Found $(\mathrm{g} / 10 \mathrm{~g})$ & \% Recovery \\
\hline 1 & 0.4001 & 0.3961 & 99.00 \\
\hline 2 & 0.4002 & 0.3988 & 99.66 \\
\hline 3 & 0.4001 & 0.3948 & 98.67 \\
\hline
\end{tabular}


RASĀYAN J. Chem.

Vol. 12 | No. 4 |2296 - 2305| October - December | 2019

\section{CONCLUSION}

The results showed the composition of the electrode membrane which gave the best results was carbon, paraffin, and ferrocene each with a ratio of $6: 3: 1$. Based on the voltammogram, the effect of the scan rate shows that on the electrode surface occurred an electrochemical reaction which later being followed by a chemical reaction. The $\mathrm{pH}$ of the solution has an effect on the cyclic hydroquinone voltammogram. $\mathrm{pH} 7$ gives a voltammogram that is closer to a reversible reaction. The validity of the hydroquinone analysis method that was using carbon/ferrocene paste as the electrode shows good results. They are also proven to be selective in the analysis of a mixture of hydroquinone and arbutin. These electrodes have excellent accuracy in recovering hydroquinone and arbutin analysis in cosmetic creams. Therefore, this method is suitable to be used in skin whitening analysis, both for hydroquinone and arbutin analysis.

\section{ACKNOWLEDGMENT}

The authors thank Faculty of Science and Technology Universitas Airlangga, Surabaya, Indonesia for the financial support through RKAT research funding in the 2018 fiscal year with contract number 1908/UN3.1.8/LT/2018.

\section{REFERENCES}

1. W. Westerhof and T.J. Kooyers, Journal of Cosmetic Dermatology, 4, 55(2005), DOI: 10.1111/j.1473-2165.2005.40202.x

2. T.C. Tsai and B.M. Hantash, Clinical Medicine: Dermatology, 1, 1 (2008)

3. Badan Pengawas Obat dan Makanan (BPOM) RI, Persyaratan Teknis Bahan Kosmetika (2011)

4. P.O. Odumosu and T.O. Ekwe, African Journal of Pharmacy and Pharmacology, 5, 231 (2010)

5. S. Siddique, P. Zahida, A. Zeeshan, and Z. Muhannad, Journal of Cosmetics, Dermatological Sciences and Applications, 2, 224 (2012), DOI:10.4236/jcdsa.2012.23042

6. P. L. Garcia, M.I. R.M. Santoro, E.R.M.K. Hackmann, A. K. Singh, J. Pharm. Biomed. Anal., 39, 764 (2005)

7. A. Chisvert, J. Sisternes, A. Balaguer, Dan A. Salvador, Talanta, 81, 530(2010), DOI:10.1016/j.talanta.2009.12.037

8. L. Zhao, L. Baoqiang, H. Yuan, Z. Zhou, and D. Xiao, Sensors, 7, 578 (2007)

9. Y.H. Lin, Y.H. Yang, S.M. Wu, Journal of Pharmaceutical and Biomedical Analysis, 44, 279 (2007)

10. K. He, X. Wang, X. Meng, H. Zheng, S.I. Suye, Sensors Actuators, B. Chem., 193, 212(2014)

11. G. Xu, B. Li, X. Luo, Sensors Actuators B. Chem., 176, 69(2013)

12. S. Hu, Y. Wang, X. Wang, L. Xu, J. Xiang, W. Sun, Sensors Actuators, B Chem.,168, 27(2012)

13. S. Wong and D. Du., Sensors, 2, 41 (2002)

14. Y. She, Y. Tang, H. Liu, P. He, Chemistry Central Journal, 4(2010)

15. M.S. Ahmad, I.M. Isa, N. Hashim, M.S. Rosmi, S. Mustafar, Int. J. Electrochem. Sci., 18, 373(2018)

16. G. Pari, S. Darmawan, dan B. Prihandoko, Procedia Environmental Sciences, 20, 342(2013)

17. M.A. Kamyabi dan F. Aghajanloo, Croatia Chemica Acta, 82(3), 599(2009)

18. H. Yaghoubian, H.K. Maleh, M.K. Khalilzadeh, F. Karimi, J. Electrochem. Sci., 4, 993 (2009)

19. S.H. Bang, S.J. Han, S.J., Kim, D.H., Journal of Cosmetic Dermatology, 34, 287(2017), DOI:10.1111/j.1473-2165.2008.00387.x

20. J. Wang, Analytical Electrochemistry, $3^{\text {rd }}$ ed., John Wiley \& Sons, Inc.,USA, (2006)

21. D.K. Jr. Gosser, Cyclic Voltammetry Simulation and of Reaction Mechanism, USA: VCH Publiser (1993)

22. X. Wang, W. Min, L. Hui, J. W. Qing, H. Pingang, and F. Yuzhi, Sensor and Actuators B, 192, 452 (2014)

23. M. Gillner, G. Moore and K. Gustafsson, Enviromental Health Criteria 157, World Health Organization, Genewa (1994)

24. A.J. Bard and L.R. Faulkner, Electrochemical Methods Fundamental and Application, $2^{\text {nd }}$. Ed., John Wiley \& Sons, Inc. New York (2001)

[RJC-5479/2019] 